\title{
ARE MOTOR AND COGNITIVE CONTROL, IMPULSIVITY AND RISK-TAKING BEHAVIOUR AS WELL AS MORAL DECISION MAKING DETERMINED BY THE ACTIVITY OF PREFRONTAL CORTEX DURING STROOP TEST?
}

\author{
Albertas Skurvydas, Dovilè Valančiene, Andrius Šatas, Dalia Mickevičiene, \\ Kazys Vadopalas, Diana Karanauskienè \\ Lithuanian Sports University, Kaunas, Lithuania
}

\begin{abstract}
Background. The main aim of our research was to determine if there was a relationship between prefrontal cortex activity during Stroop test (dependent variables) and variables of "Go/NoGo", Balloon Analogue Risk Task, impulsivity score, different tests of cognitive functions, moral decisions tests (altruistic or egoistic), Fitts-like motor control task, five character traits, emotional intelligence, mood, sleepiness and perceived stress, total physical activity of subjects (independent variables).

Methods.In total, 20 undergraduate students (mean age were 21.3, SD =1) met the criteria and agreed to participate in this study.

Results. Our research has shown that different brain functional outcomes, that is speed-accuracy motor control, inhibition response control and cognitive performance, risky-taking behaviour and impulsivity control, management of emotion, personality consciousness and physical activity have a common correlation with the increase in prefrontal cortex activity (measured by fNIRS) during Stroop test.

Conclusion. Our studies have clearly shown that different brain functional outcomes, that is speed-accuracy motor control, inhibition response control and cognitive performance, risky-taking behaviour and impulsivity control, management of emotion, personality consciousness and physical activity have a common correlation with the increase in prefrontal cortex activity (measured by fNIRS) during Stroop test. Considerable number of studies are needed to understand what is the functional essence of these relationships, but currently there is an increase of research establishing correlations between motor behaviour and cognition control.
\end{abstract}

Keywords: prefrontal cortex, motor and cognitive control, impulsivity, risk-taking, moral decision making.

\section{INTRODUCTION}

$\mathrm{B}$ ehavioural inhibition, sustained attention, decision making, executive functions and self-control are basic behaviour determinants of healthy brain (Bari \& Robbins, 2013; Barkley, 1997; Diamond, 2013; Hare, Camerer, \& Rangel, 2009; Heatherton \& Wagner, 2011; Pratt, Winchester, Egerton, Cochran, \& Morris, 2008). It has been concluded that low self-control is a significant risk factor for a broad range of personal and interpersonal problems, while higher scores on self-control correlated with a higher grade point average, better adjustment (fewer reports of psychopathology, higher selfesteem), less binge eating and alcohol abuse, better relationships and interpersonal skills, secure attachment, and more optimal emotional responses (Tangney, Baumeister, \& Boone, 2004). The childhood self-control predicts physical health, substance dependence, personal finances, and criminal offending outcomes, following a gradient of self-control (Moffitt et al., 2011). Thus, the executive functions and self-control are included as 
most important mechanisms in motor and cognition control (Diamond, 2013; Heatherton \& Wagner, 2011; Wolpert \& Landy, 2012).

A number of tests are known to directly or indirectly assess certain self-control and executive function components. For example, response inhibition paradigm ("Go/NoGo" and "Stroop" tests) (Chikazoe, 2010; Kueider, Parisi, Gross, \& Rebok, 2012), behavioural decision-making tasks (such as the Iowa Gambling Task and Balloon Analogue Risk Task, BART) (Buelow \& Barnhart, 2017; Lejuez et al., 2002), impulsivity score (BIS11) (Patton, Stanford, \& others, 1995), Fitts-like motor control task (Bertucco, Bhanpuri, \& Sanger, 2015), five character traits (conscientiousness, which is related to impulse control) (Costa \& MacCrae, 1992), emotional intelligence (Schutte et al., 1998), different tests of cognitive functions (Reeves, Winter, Bleiberg, \& Kane, 2007) and moral decisions tests (altruistic or egoistic) (Starcke, Polzer, Wolf, \& Brand, 2011).

Frontal and prefrontal cortex is one of major brain structures responsible for cognition and motor control as well as decision-making, selfcontrol and executive functions (Bechara, 2005; Cohen \& Poldrack, 2009; Diamond, 2013; Dunning, Ghoreyshi, Bertucco, \& Sanger, 2015; Heatherton \& Wagner, 2011; Krain, Wilson, Arbuckle, Castellanos, \& Milham, 2006; Miller \& Cohen, 2001; Shadmehr, Smith, \& Krakauer, 2010; Wolpert \& Landy, 2012).

It is generally accepted that the more complex the cognition and motor control, the more prefrontal and frontal cortex are activated in healthy people. Recently it has been established that neurons in the frontal cortex become more active when the activity is more risky (Krain et al., 2006; Schultz, O'Neill, Tobler, \& Kobayashi, 2011). Taken together, if cognitive and motor control is mentally demanding, then frontal and prefrontal cortex activity is decreased due to self-control and impulsivity control diminishing (Muraven \& Baumeister, 2000; Qi et al., 2015), due to aging (Pratt et al., 2008), in suicidal patients (Desmyter, van Heeringen, \& Audenaert, 2011), due to impaired control over drinking (Weafer et al., 2015).

The main aim of our research was to find out if there was a relationship between prefrontal cortex activity during Stroop test (dependent variables) and variables of "Go/NoGo", Balloon Analogue Risk Task, impulsivity score, different tests of cognitive functions, moral decisions tests (altruistic or egoistic), Fitts-like motor control task, five character traits, emotional intelligence, mood, sleepiness and perceived stress, total physical activity of subjects (independent variables). We expected that there would be a strong correlation between the prefrontal cortex activity, established fNIRS help (Ferrari \& Quaresima, 2012) during Stroop test, which demands executive function and self-control, and various motor, cognitive and emotional control tests, which determine executive functions and self-control). In this case we believe that by relatively simple tests we will get a clearer understanding of how the brain functions and executive self-control mechanisms operate.

\section{METHODS}

Participants. Twenty seven men were assessed for eligibility. Participant inclusion criteria were: age between 20 and 30 years; non-smoker, no excessive sporting activities, i.e., $<3$ times per week, and exclusion criteria were: history of $d r u g /$ alcohol dependence or abuse, night/shift-work, medications that could influence central nervous system activity, and history of any neurological or psychiatric disorders. In total, 20 undergraduate students (age: $21.3 \pm 1.0$ yr.) met the criteria and agreed to participate in this study. All participants were right-handed, and had normal or correctedto-normal vision. The present study was approved by the Human Research Ethics Committee. All participants independently provided written and verbal informed consent in accordance with the Declaration of Helsinki. The research was approved by the local Ethics Committee (The Kaunas Regional Ethics Committee, No. BE-2-40), performed in accordance with the Declaration of Helsinki.

Experimental design. To attain a stable level of performance, one week before the experimental visits, participants attended a familiarization session during which they were introduced to the experimental procedures for cognitive and motor testing. The participants then were given three self-report measures, which incorporated measures of stress level in the past month, emotional intelligence and personality traits. During the second visit, a functional near-infrared spectroscopy (fNIRS) probe was attached to the frontal areas of the forehead. The participant was asked to rest in a sitting position for $5 \mathrm{~min}$ and 
then complete the Stroop colour and word task. Subsequently, the participant completed code substitution, mathematical processing, go/no-go, and code substitution delayed tasks, and performed pursuit tracking. The participant then completed a self-report measure about his mood and physical activity level in the past week. The participant was asked to complete simple reaction, maximal velocity and speed-accuracy motor tasks. The participant then completed a self-report measure about his motivation toward the speed-accuracy motor task performance. During third day, the participant was asked to complete BART and self-report measures about impulsivity and moral decision making. Thus, each participant completed all four visits. Participants were given instructions to sleep for at least $7 \mathrm{~h}$, refrain from consumption of alcohol, and avoid any intense physical and mental work the day before each further visit. Participants were also instructed not to consume caffeine and nicotine for at least $3 \mathrm{~h}$ before each visit.

Assessment of chronic stress. Perceived stress last month was assessed using the Perceived Stress Scale-14 (PSS-14) (S. Cohen, Kamarck, \& Mermelstein, 1983). The PSS-14 is a 14-item questionnaire divided into two subscales: stress and coping. The items are answered on a fivepoint scale ranging from 0 (never) to 4 (very often), and each subscale, with seven relevant items, are summed to produce a raw score in the range of 0 to 28 . Total scores range from 0 to 56 , with higher scores representing higher perceived stress level last month.

Assessment of emotional intelligence. Emotional intelligence was assessed using the Schutte Self-Report Emotional Intelligence Test (SSREIT) (Schutte et al., 1998). The SSREIT is a 33-item questionnaire divided into six 4 subscales: perception of emotion assessed by 10 items, managing own emotions assessed by 9 items, managing others' emotions assessed by 8 items, and utilization of emotions assessed by 5 items. The items are answered on a five-point scale ranging from 1 (strongly agree) to 5 (strongly agree). Total score range from 33 to 165 , with the higher scores indicating greater ability in emotional intelligence.

Assessment of personality. Big Five personality traits was assessed using the Neo Five-Factor Inventory (NEO-FFI) (Costa \& MacCrae, 1992) .The NEO-FFI is a 60-item questionnaire divided into five subscales: neuroticism, extroversion, openness to experience, agreeableness and conscientiousness. The items are answered on a five-point scale ranging from 0 (strongly disagree) to 4 (strongly agree), and each subscale, with twelve relevant items, are summed to produce a raw score in the range of 0 to 48 , with higher scores reflecting greater endorsement of the specific trait.

Assessment of mood. Current mood was assessed using the Brunel Mood Scale (BRUMS) (Terry, Lane, \& Fogarty, 2003). The BRUMS is a 24-item questionnaire divided into six subscales: anger, confusion, depression, fatigue, tension, and vigour. The items are answered on a five-point scale ranging from 0 (not at all) to 4 (extremely), and each subscale, with four relevant items, are summed to produce a raw score in the range of 0 to 16 , with higher scores reflecting greater endorsement of the specific mood state.

Assessment of physical activity level. The physical activity level was assessed using the International Physical Activity QuestionnaireShort Form (IPAQ-SF) (Craig et al., 2003). In the current study, we included a six-items assessing the frequency and duration of moderate and vigorous intensity activity and walking physical activity. These data were summarized by weighting the energy expenditure for these categories of activity to produce MET-minutes/week of physical activity, with higher scores reflecting higher amount of activity.

Assessment of motivation. Based on scale used in a previous studies (Kleih \& Kübler, 2013; Solianik et al., 2016), motivation with regard to the speed-accuracy motor task performance was assessed on a visual analog scale (VAS) ranging from 1 (not motivated at all) to 10 (extremely motivated) on a $10 \mathrm{~cm}$ long horizontal line.

Assessment of impulsivity. Impulsivity was assessed using the Barratt Impulsiveness Scale Version 11 (BIS-11) (Patton et al., 1995). The BIS11 is a 30-item questionnaire divided into three subscales: attentional impulsiveness assessed by 8 items, motor impulsiveness assessed by 11 items, and nonplanning impulsiveness assessed by 11 items. The items are answered on a four-point scale ranging from 1 (rarely/never) to 4 (almost always/ always). Total score range from 30 to 120 , with higher scores representing higher impulsivity.

Assessment of everyday moral decision making. Moral decision making was assessed using the Everyday Moral Decision-Making Task (EMDM) (Starcke et al., 2011). EMDM is a 
20-item questionnaire, half of which represents high emotional personal dilemmas, and the remaining items represent low emotional impersonal dilemmas. The items are answered with "yes" (egoistic decision) or "no" (altruistic decision). The percentage of altruistic judgments was calculated.

Assessment of risky decision making. Risky decision making was assessed with the Psychology Experiment Building Language (PEBL) test battery using the Balloon Analog Risk Task (BART) (Lejuez et al., 2002; Mueller \& Piper, 2014). During BART, the average number of pumps made on trials in which the balloon did not explode was examined.

Assessment of prefrontal cortex activity. Activity of prefrontal cortex was monitored using fNIRS (Masataka, Perlovsky, \& Hiraki, 2015). Measurements were performed on a continuous wave system (fNIR Imager 1100, fNIR Devices LLC, USA), using a flexible 16-optode probe set (consisting of 10 photodetectors and 4 light emitters each using 730 and 850 wavelength of light) placed over the eyebrows on the participant's forehead and centered vertically. The sensor has a temporal resolution of $500 \mathrm{~ms}$ per scan with 2.5 $\mathrm{cm}$ source-detector separation allowing for about $1.25 \mathrm{~cm}$ penetration depth and 16 measurement locations on a rectangular grid covering the forehead region. For data acquisition COBI Studio software was used (Ayaz et al., 2011). The signals of all channels were verified before recording. Data analysis was performed using fNIRSoft analysis software (BIOPAC Systems Inc., USA). Oxygenated haemoglobin (HBO) concentrations were calculated from the raw data by solving the modified Beer-Lambert equation. Data were filtered to remove HF noise, physiological artefacts such as heartbeats, and motion-derived artefacts. The relative changes in the concentrations of HBO were acquired for all participants in all 16 channels and the data were averaged.

Assessment of cognitive performance. To assess cognitive performance, the Automated Neuropsychological Assessment Metric (ANAM4, VistaLifeSciences, USA) was administered (Reeves et al., 2007; Woodhouse et al., 2013). The test battery included the following chosen tasks measuring three scores: accuracy defined as the percentage of correct responses, mean reaction time for responses time, and throughput which is considered a measure of effectiveness or cognitive efficiency, and is a combination of reaction time and accuracy (Thorne, 2006).

Go/No-Go Task (GNGT) evaluates inhibitory control (Diamond, 2013). During this task, the participant was instructed to respond as quickly as possible to an " $\mathrm{x}$ " on the screen by pressing the left mouse button each time the stimulus appeared; when an "o" appeared, the participant was required to withhold his response. This task comprised 120 trials. The go ("x") stimuli occurred in $80 \%$ of trials and the no-go ("o") stimuli occurred in the remaining $20 \%$ of trials.

Mathematical Processing Task (MPT) evaluates working memory (Reeves et al., 2007; Woodhouse et al., 2013). During this task, an arithmetic problem requiring an addition and subtraction of three single-digit numbers was displayed (e.g., " $4-2+1=$ "). The participant was instructed to respond as quickly as possible and to press the left mouse button if the answer to the equation was $>5$ or to press the right mouse button if the answer was $<5$. The correct answer may be any number from 1 to 9, except 5. This task comprised 20 trials.

Code Substitution (CST) and Code Substitution Delayed Tasks (CSDT) evaluate immediate and delayed recognition memory (Reeves et al., 2007; Woodhouse et al., 2013). Participant was presented to 9 different symbol-digit pairs and was instructed to remember as many symbol-digit pairs as possible, in any order, as they will be asked to recall them later. During CST and CSDT, the participant was presented only with a single "test" pair and was instructed to respond as quickly as possible by press the left mouse button if the pair is correct and consistent with pairings presented earlier or by pressing the right mouse button if the pair is incorrect. CST comprised 72 trials and CSDT comprised 32 trials.

The Lithuanian version of the Stroop colour and word task (SCWT) was used to evaluate information processing speed and executive functioning (Golden \& Freshwater, 1978) and was created using OpenSesame software (Mathôt, Schreij, \& Theeuwes, 2012) based on the previous English version used in an ANAM-4. The participant was instructed to respond as quickly as possible to the colour used to print the colour names on the screen by pressing an associated keyboard key (A for red, S for green, D for blue, and $\mathrm{F}$ for yellow). On each trial, a word indicating a colour name ("žalia" (green), "mèlyna" (blue), "raudona" 
(red), or "geltona" (yellow)) was presented on the screen in red, green, blue, or yellow for $2 \mathrm{~s}$. The task comprised 100 congruent (e.g., the word "blue" printed in blue) and 100 incongruent (e.g., the word "green" printed in yellow) stimuli presented in random order. During Stroop colour and word task, mean reaction time and percentage error were examined.

Assessment of motor tasks performance. Psychomotor coordination was assessed with the ANAM-4 battery during the pursuit tracking task (PTT) (Woodhouse et al., 2013). During PTT task, the participant was instructed to move the computer mouse so that the mouse cursor tracked a moving box with a + symbol inside. The cursor was required to remain inside the box and be kept as close to the + as possible as it moves across the screen in a circular pattern for $120 \mathrm{~s}$. The mean distance from the + target was recorded.

The simple motor reaction time was assessed with the simple reaction task (SRT) (Woodhouse et al., 2013), maximal speed was assessed with the maximal velocity task (MVT), and motor control was assessed with the speed-accuracy motor task (SAMT) (Mickevičienè, Skurvydas, \& Karanauskienè, 2015). Tasks were performed using an analyser of dynamic parameters of human movements (DPA-1; Kaunas, Lithuania). The participant positioning has been described previously (Mickevičienė et al., 2015; Zuoza et al., 2009). During each task, the participant was required to position the $3.5-\mathrm{mm}$ radius handle symbol in the start zone (green circle, $10-\mathrm{mm}$ radius) on the computer screen using the handle of the apparatus. Then program generated an auditory stimulus and a target (a red circle, 7-mm radius) appeared in the same place on the computer screen in front of the start zone and at a $170-\mathrm{mm}$ distance. During SRT, the participant was asked to react as quickly as possible to the target appearing on the computer by pushing the handle. SRT comprised 10 trials. During this task, the mean reaction time (RT) was recorded. During MVT task, the participant was asked to move the handle to the target with maximal speed. MVT comprised 5 trials. During this task, the mean maximal velocity (Vmax) was recorded. During SAMT, the participant was asked to react to the target appearing on the computer screen and to reach the target while moving the handle forward as quickly as possible and in the most accurate trajectory. The endpoint of the movement was recorded when the cursor stopped in the target circle and stayed there for at least $0.02 \mathrm{~s}$. MVT comprised 20 trials. The RT, average velocity (V), Vmax, and distance (D) of total motion from the initial to the final position were recorded. The intraindividual variability (coefficient of variation, CV) was calculated.

Statistical analysis. Data are reported as means and standard deviations (SDs). Pearson's correlation coefficients (r) were used to analyse the relationships between prefrontal cortex activity during Stroop test (dependent variables) and variables of "Go/NoGo", Balloon Analogue Risk Task, impulsivity score, different tests of cognitive functions, moral decisions tests (altruistic or egoistic), Fitts-like motor control task, five character traits, emotional intelligence, mood, sleepiness and perceived stress, total physical activity of subjects (independent variables). The level of significance of difference between variables was set at $p<.05$. All statistical analyses were performed using SPSS (version 21.0; IBM Corp., USA).

\section{RESULTS}

The average of total physical activity was 6224.2, $(S D=1245.2)$ METmin/week. Motivation was 8.5 (1.9) points. RT correct, RT incorrect and percent of correct responses during "Go/NoGo" test was respectively $327.7(S D=25.9) \mathrm{ms}, 273.7$ $(S D=13.4) \mathrm{ms}$ and $96.2(S D=3.3) \%$. RT incorrect was significantly shorter than RT correct $(p<.01)$. RT, percent correct and throughput of mathematical processing was respectively $1837.8 \mathrm{~ms}(S D=248.8)$, $86.4 \%(S D=13.1)$ and $28.9(S D=6.1)$. The result of CS and CSD is shown in Table 1. The distance Pursuit tracking test was $6.2(S D=1.2) \mathrm{mm}$. The Table 1. The average (SD) of code
substitution (CS) and code substitution
delayed (CSD) tasks

Note. Data are presented as average (standard deviation).

\begin{tabular}{|c|c|c|c|c|c|}
\hline $\begin{array}{c}\text { CS RT } \\
(\mathbf{m s})\end{array}$ & $\begin{array}{c}\text { CS percent } \\
\text { correct }\end{array}$ & $\begin{array}{c}\text { CS } \\
\text { throughput }\end{array}$ & $\begin{array}{c}\text { CSD RT } \\
\text { (ms) }\end{array}$ & $\begin{array}{c}\text { CSD percent } \\
\text { correct }\end{array}$ & $\begin{array}{c}\text { CS } \\
\text { throughput }\end{array}$ \\
\hline 867.9 & 97.7 & 67.9 & 935.4 & 93.3 & 61.1 \\
$(112.5)$ & $(1.7)$ & $(7.5)$ & $(145.2)$ & $(6.4)$ & $(10.1)$ \\
\hline
\end{tabular}


Table 2. The average (SD) of motor control variables

\begin{tabular}{|c|c|c|c|c|c|c|c|c|c|}
\hline $\begin{array}{c}\text { RT simple } \\
(\mathbf{s})\end{array}$ & $\begin{array}{c}\text { Vmax } \\
(\mathbf{m} / \mathbf{s})\end{array}$ & $\begin{array}{c}\text { RT } \\
(\mathbf{s})\end{array}$ & $\begin{array}{c}\text { CV of RT } \\
(\mathbf{\%})\end{array}$ & $\begin{array}{c}\text { VA } \\
(\mathbf{m} / \mathbf{s})\end{array}$ & $\begin{array}{c}\text { CV of VA } \\
(\mathbf{\%})\end{array}$ & $\begin{array}{c}\text { VM } \\
(\mathbf{m} / \mathbf{s})\end{array}$ & $\begin{array}{c}\text { CV of VM } \\
(\mathbf{\%})\end{array}$ & $\begin{array}{c}\text { S } \\
(\mathbf{m})\end{array}$ & $\begin{array}{c}\text { CV of S } \\
(\mathbf{\%})\end{array}$ \\
\hline 0.21 & 1.7 & 0.26 & 15.2 & 0.174 & 29.7 & 0.63 & 16.1 & 0.19 & 7.7 \\
$(0.02)$ & $(0.32)$ & $(0.02)$ & $(4.1)$ & $(0.02)$ & $(5.6)$ & $(0.14)$ & $(5.4)$ & $(0.01)$ & $(3.6)$ \\
\hline
\end{tabular}

Note. Data are presented as average (standard deviation).

\begin{tabular}{|c|c|c|c|}
\hline Orange (pumps) & Yellow (pumps) & Blue (pumps) & Total (pumps) \\
\hline 3.5 & 5.1 & 11.4 & 8.1 \\
$(1.1)$ & $(1.3)$ & $(5.8)$ & $(3.1)$ \\
\hline
\end{tabular}

Table 3. The average of risk-taking behaviour during BART Balloon Analogue Risk Task

Note. Data are presented as average (standard deviation).

\begin{tabular}{|c|c|c|c|}
\hline Attentional & Motor & Nonplanning & Total \\
\hline 15.3 & 20.0 & 22.4 & 57.7 \\
$(3.1)$ & $(3.6)$ & $(5.1)$ & $(9.5)$ \\
\hline
\end{tabular}

Table 4. The average of impulsivity of BIS-11 Barratt Impulsiveness Scale Version 11

Note. Data are presented as average (standard deviation).

\begin{tabular}{|c|c|c|c|c|}
\hline $\begin{array}{c}\text { Perception of } \\
\text { emotion }\end{array}$ & $\begin{array}{c}\text { Managing of } \\
\text { emotion }\end{array}$ & $\begin{array}{c}\text { Managing others } \\
\text { emotion }\end{array}$ & $\begin{array}{c}\text { Utilization of } \\
\text { emotion }\end{array}$ & Total \\
\hline 34.9 & 36.2 & 28.6 & 22.6 & 122.3 \\
$(7.2)$ & $(5.6)$ & $(4.1)$ & $(4.4)$ & $(17.4)$ \\
\hline
\end{tabular}

Table 5. The average (SD) of Schutte Self Report Emotional Intelligence Test

Note. Data are presented as average (standard deviation).

\begin{tabular}{|c|c|c|c|c|c|}
\hline Anger & Confusion & Depression & Fatigue & Tension & Vigour \\
\hline 0.7 & 0.6 & 0.7 & 2.5 & 1.3 & 6.9 \\
$(1.5)$ & $(1.3)$ & $(1.6)$ & $(2.2)$ & $(1.9)$ & $(1.6)$ \\
\hline
\end{tabular}

Table 6. The average $(S D)$ variables of BRUMS Brunel Mood Scale

Note. Data are presented as average (standard deviation).

\begin{tabular}{|c|c|c|c|c|}
\hline $\begin{array}{c}\text { Emotionality or } \\
\text { neuroticism }\end{array}$ & Extraversion & $\begin{array}{c}\text { Openness to } \\
\text { experience }\end{array}$ & Agreeableness & Conscientiousness \\
\hline 20.1 & 28.3 & 20.1 & 29.3 & 32.2 \\
$(4.5)$ & $(7.4)$ & $(2.9)$ & $(5.7)$ & $(8.3)$ \\
\hline
\end{tabular}

Table 7. Character traits according NEO-FFI NEO Five Factor Inventory

Note. Data are presented as average (standard deviation).

results of motor control variables during speedaccuracy task are shown in Table 2. Time to VM was $0.24(S D=0.04) \mathrm{s} ; \mathrm{VM} / \mathrm{Vmax}-38.3(S D=$ 9.2)\%. RT during speed-accuracy task was by 124.8 $(S D=14.8) \%$ longer compared to RT simple $(p<$ $.05)$. The averages (SD) of risk-taking during BART Analogue risk task and Barat impulsiveness is show respectively in Table 3 and Table 4 . The altruistic answers (\%) of low, high and total emotional dilemmas are respectively $56.0(S D=15.7) \%, 63.0$ $(S D=17.6) \%$ and $59.5(S D=12.3) \%$. The results of emotional intelligence are shown in Table 5. The total stress, stress and coping perceived stress (PSS14 Perceived stress scale-14) was respectively 22.0 $(S D=5.5), 18.3(S D=4.1)$ and $24.3(S D=2.5)$. The average (SD) mood variables are shown respectively in Table 6. The results of character traits are shown in the Table 7. Rest, Stroop HBO were $1.1(S D=$ 1.1), $2.1(S D=1.5)$. Stroop/rest ratio HBO was 1.84 $(S D=2.3)$. Stroop RT was $640.2(S D=63.4) \mathrm{ms}$; error $-4.3(S D=2.4) \%$. RT of STROOP test was by $300.2(S D=20.8) \%$. 
The increases of activity of prefrontal cortex during Stroop test is significantly correlated with motor control variables (RT, VM, S and CV of RT during speed-accuracy task respectively: -.71 ; $.79 ;-.77 ;-.69)$, RT correct of "Go/NoGo" (-.64), impulsivity (-.83); risk-taking behaviour (total pumps: .74), emotional intelligence (managing of emotion: .87), character traits (conscientiousness: $.67)$, total physical activity (.73); however there was no significant relation with perceived stress, mood, altruistic total answers, CS, SCD, mathematical processing and Stroop test variables, as well as, motivation level.

\section{DISCUSSION}

The main findings of our studies are based on correlation data: the more increases prefrontal cortex activity during Stroop (established fNIRS help, Ferrari and Quaresima, 2012), the faster and more stable speed and accuracy motor planning, the faster and more accurate movement performance, the greater inhibition during "Go/NoGo" test, the greater risk, the less impulsivity, the better emotional control, character is of conscious type, as well as more total physical activity. However, there was no significant relation with perceived stress, altruistic total answers, CS, SCD, mathematical processing and Stroop test variables, as well as HR variability (RMSD).

Obtained significant correlations were not unexpected, since, according to studies by other researchers that decreased activity prefrontal and frontal cortex is marker of failure of self-control (Desmyter et al., 2011; Pratt et al., 2008; Qi et al., 2015), we expected to find between increased prefrontal cortex activity during Stroop test and various task performance, which demand prefrontal cortex activity.

Motor control. There is no doubt that motor planning and control during speed-accuracy task is dependent on optimal activity of frontal and prefrontal cortex because the brain is characterized by trade-off between speed and accuracy, and this is related to perceived risk (Bertucco et al., 2015). Based on research in recent years, we suggest that motor control and behaviour may be viewed as a problem of maximizing the utility of movement outcome in the face of sensory, motor and task uncertainty (Wolpert \& Landy, 2012). For example, if noise in the motor system increases as the movement speed increases, then increasing accuracy can only be achieved by decreasing the speed of movement (Harris \& Wolpert, 1998). Taken together, it can be easily understood that the velocity of speed-accuracy motor planning and its stability (intraindividual variability), as well as speed and accuracy of motor performance must be efficiently controlled by prefrontal and frontal cortex. On the other hand, we can speculate that our speed-accuracy task variables predict/show "healthy activity" of prefrontal cortex. Of course, if the movement is very well learned and simple, then prefrontal brain activity might be slightly lower because the brain tries to control the tasks that they would require effort management as little as possible (Kool, McGuire, Rosen, \& Botvinick, 2010).

Response Inhibition control and cognitive function. We were not surprised that in our case the faster inhibition of the task (RT) during " $\mathrm{Go} /$ NoGo" test directly correlated significantly with increases in prefrontal brain activity during Stroop test because the reaction inhibition task requires working memory, attention, concentration and flexibility of executive function (Verbruggen \& Logan, 2008). We were more surprised that there was no significant correlation with inhibition error during „Go/NoGo"test because people with increased impulsivity (Logan, Schachar, \& Tannock, 1997) or with substance abuse problems (Monterosso, Aron, Cordova, Xu, \& London, 2005) make more errors in the "Go/NoGo" task than healthy control subjects. It was also unexpected that there was no significant correlation with Stroop test variables because "Go/NoGo" and Stroop tests belong to the same response inhibition paradigm (Chikazoe, 2010; Kueider et al., 2012).

Risk-taking behaviour (BART) and the impulsivity (BIS-11). In our case the established correlation relationship between mobilization prefrontal cortex activity during Stroop test and total pumps during BART test is consistent with data of other researchers (J. R. Cohen \& Poldrack, 2009; Kohno, Morales, Ghahremani, Hellemann, \& London, 2014; Schonberg et al., 2012). Namely, Schnonberg et al. (2012) scanned participants using fMRI while they completed the Balloon Analog Risk Task. They found that areas previously linked to risk and risk-taking (bilateral anterior insula, anterior cingulate cortex, and right dorsolateral prefrontal cortex) were activated as participants continued to inflate balloons. Other researchers showed that in the balloon test case, 
the more risk the participants take, the greater the increase in prefrontal activity (J. R. Cohen \& Poldrack, 2009; Kohno et al., 2014). Evidence from neuropsychological, neuroimaging, and animal studies suggest that decision making under risk involves a network of cortical and subcortical regions including orbitofrontal cortex (OFC), dorsolateral prefrontal cortex (DLPFC), parietal cortices, and caudate, anterior cingulate cortex (ACC) and thalamus (Krain et al., 2006).

The correlation analysis shows that impulsivity (BIS-11) inversely significantly related to mobilization of prefrontal cortex activity during BART. Qi et al. (2015) showed that there was a significant negative correlation between the risk-related DLPFC activation during the active BART and the Barratt impulsivity scale (BIS-11) scores. This is also consistent with our data that the relationship between mobilization of prefrontal cortex activity during Stroop test and BART total balloon was positive, while with BISS-11 impulsivity the score was negative. Besides, it has been recently shown that BART, impulsivity, and sensation seeking scores loaded on separate factors (Meda et al., 2009).

Impulsivity is a complex and multifaceted construct, comprising of impaired behavioural inhibition, increased reward sensitivity, acting without thinking, and favouring immediate rewards over long-term goals (Reynolds, Ortengren, Richards, \& de Wit, 2006). Generally, both impulsivity and low self-control are related to increased levels of risk-taking behaviour such as aggression, substance use, criminal behaviour, reckless driving and risky sexual behaviour (Feil et al., 2010; Griffin, Scheier, Acevedo, Grenard, \& Botvin, 2012; Stanford, Greve, Boudreaux, Mathias, \& L. Brumbelow, 1996).

Impulsivity and self-control are believed to stem from different neurological bases (Lieberman, 2007). The neural structures involved in impulsivity are activated under conditions that promote automatic, implicit or non-conscious processing of information (Lieberman, 2007). In contrast, self-control is reflected in higher cognitive processes that are experienced as intentional and effortful including implementation of goals and plans and inhibition (Cabeza \& Nyberg, 2000). Low self-control may be related to risk-taking behaviour because individuals with low selfcontrol have difficulty suppressing actions which are inappropriate (Verbruggen \& Logan, 2008).
To measure people's sensitivity of the dopamine system, the Balloon Analogue Risk Task (Lejuez et al., 2002) was employed. The larger the balloon sizes the higher the probability of the explosion as well as the larger the collectable reward if the explosion is avoided. Several studies have shown that people's risk-taking tendencies are a function of the availability of dopamine receptors in the midbrain (Bijleveld \& Veling, 2014; Buckholtz et al., 2010; Driver-Dunckley, Samanta, \& Stacy, 2003; Zald et al., 2008). Taken together, prior research suggests that people who score high on risk-taking measures, and on the BART specifically, have a more sensitive dopamine system. However, previous studies in economics have shown that individual risk-sensitivity tends to be contextdependent, such that the same individual can be risk-averse in one domain but risk-seeking in another (Hanoch, Johnson, \& Wilke, 2006).

Emotional intelligence, character traits and altruistic decision making. It was not unexpected that mobilization of prefrontal cortex activity during Stroop task very strongly related to one of factor of EI, that is managing of emotion, and to character traits (conscientiousness) because they are both linked to self-control. For example, Costa and MacCrae (1992) and Gerlach et al. (2015) concluded that conscientiousness is related to impulse control and self-discipline. We did not expect to find a strong correlation between the increases of prefrontal activity and altruistic decision making because altruistic decision making is more related to emotional component of brain (limbic system) and orbital and ventromedial prefrontal cortices (Pascual, Rodrigues, \& Gallardo-Pujol, 2013) rather than DLPFC prefrontal cortex (Raine \& Yang, 2006).

Mood, stress and PA. There was a significant relationship between increase in prefrontal cortex activity during Stroop test and PA, and this perhaps can be explained by the fact that PA trains self-control "structures" (Bardo \& Compton, 2015). Generally, the findings of Hillman et al. (2015) have indicated that daily physical activity is related to greater volume and integrity of brain structure, efficient and effective brain function, and superior executive control. Kelley et al. (2015) concluded that the capacity for selfregulation allows people to control their thoughts, behaviours, emotions, and desires. Such failures frequently occur following exposure to highly tempting cues, during negative moods. However, 
we did not find any link between cortex activity and perceived stress and mood variable.

\section{CONCLUSIONS}

In conclusion, our studies have clearly shown that different brain functional outcomes, that is speed-accuracy motor control, inhibition response control and cognitive performance, risky-taking behaviour and impulsivity control, management of emotion, personality consciousness and physical activity have a common correlation with the increase in prefrontal cortex activity (measured by fNIRS) during Stroop test. Considerable number of studies are needed to understand what is the functional essence of these relationships, but currently there is an increase of research establishing correlations between motor behaviour and cognition control (Cook, 2016; Hillman et al., 2015; Seegelke \& Schack, 2016).

Compliance with ethical standards. Conflict of interest. The authors declare that they have no conflict of interest.

Ethical approval. All procedures performed in studies involving human participants were in accordance with the ethical standards of the local Ethics Committee and with the 1964 Declaration of Helsinki and its later amendments or comparable ethical standards.

Informed consent. Written informed consent was obtained from all participants included in the study.

\section{REFERENCES}

Ayaz, H., Shewokis, P. A., Curtin, A., Izzetoglu, M., Izzetoglu, K., \& Onaral, B. (2011). Using MazeSuite and Functional Near Infrared Spectroscopy to Study Learning in Spatial Navigation. Journal of Visualized Experiments, (56). https://doi.org/10.3791/3443

Bardo, M. T., \& Compton, W. M. (2015). Does physical activity protect against drug abuse vulnerability? Drug and Alcohol Dependence, 153, 3-13. https://doi. org/10.1016/j.drugalcdep.2015.05.037

Bari, A., \& Robbins, T. W. (2013). Inhibition and impulsivity: Behavioral and neural basis of response control. Progress in Neurobiology, 108, 44-79. https:// doi.org/10.1016/j.pneurobio.2013.06.005

Barkley, R. A. (1997). Behavioral inhibition, sustained attention, and executive functions: constructing a unifying theory of ADHD. Psychological Bulletin, 121(1), 65-94.

Bechara, A. (2005). Decision making, impulse control and loss of willpower to resist drugs: A neurocognitive perspective. Nature Neuroscience, 8(11), 1458-1463. https://doi.org/10.1038/nn1584

Bertucco, M., Bhanpuri, N. H., \& Sanger, T. D. (2015). Perceived Cost and Intrinsic Motor Variability Modulate the Speed-Accuracy Trade-Off. PLOS ONE, 10(10), e0139988. https://doi.org/10.1371/journal. pone.0139988

Bijleveld, E., \& Veling, H. (2014). Separating chokers from nonchokers: predicting real-life tennis performance under pressure from behavioral tasks that tap into working memory functioning. Journal of Sport \& Exercise Psychology, 36(4), 347-356. https://doi. org/10.1123/jsep.2013-0051

Buckholtz, J. W., Treadway, M. T., Cowan, R. L., Woodward, N. D., Li, R., Ansari, M. S., ... Zald, D. H. (2010). Dopaminergic network differences in human impulsivity. Science (New York, N.Y.), 329(5991), 532. https://doi.org/10.1126/science.1185778

Buelow, M. T., \& Barnhart, W. R. (2017). The influence of math anxiety, math performance, worry, and test anxiety on the Iowa Gambling Task and Balloon Analogue Risk Task. Assessment, 24(1), 127-137. https://doi.org/10.1177/1073191115602554

Cabeza, R., \& Nyberg, L. (2000). Neural bases of learning and memory: Functional neuroimaging evidence. Current Opinion in Neurology, 13(4), 415421.

Chikazoe, J. (2010). Localizing performance of go/no-go tasks to prefrontal cortical subregions: Current Opinion in Psychiatry, 23(3), 267-272. https://doi.org/10.1097/ YCO.0b013e3283387a9f

Cohen, J. R., \& Poldrack, R. A. (2009). The neural correlates of multiple forms of self-control. Neuroimage, 47. https://doi.org/10.1016/S1053-8119(09)71941-X

Cohen, S., Kamarck, T., \& Mermelstein, R. (1983). A Global Measure of Perceived Stress. Journal of Health and Social Behavior, 24(4), 385-396. https://doi. org/10.2307/2136404

Cook, J. (2016). From movement kinematics to social cognition: the case of autism. Philosophical Transactions of the Royal Society of London. Series B, Biological Sciences, 371(1693). https://doi.org/10.1098/ rstb.2015.0372

Costa, P. T., \& MacCrae, R. R. (1992). Revised NEO personality inventory (NEO PI-R) and NEO fivefactor inventory (NEO-FFI): Professional manual. Psychological Assessment Resources, Incorporated.

Craig, C. L., Marshall, A. L., Sjöström, M., Bauman, A. E., Booth, M. L., Ainsworth, B. E., ... Oja, P. (2003). International physical activity questionnaire: 12-Country reliability and validity. Medicine and 
Science in Sports and Exercise, 35(8), 1381-1395. https://doi.org/10.1249/01.MSS.0000078924.61453.FB

Desmyter, S., van Heeringen, C., \& Audenaert, K. (2011). Structural and functional neuroimaging studies of the suicidal brain. Progress in Neuro-Psychopharmacology \& Biological Psychiatry, 35(4), 796-808. https://doi. org/10.1016/j.pnpbp.2010.12.026

Diamond, A. (2013). Executive Functions. Annual Review of Psychology, 64, 135-168. https://doi. org/10.1146/annurev-psych-113011-143750

Driver-Dunckley, E., Samanta, J., \& Stacy, M. (2003). Pathological gambling associated with dopamine agonist therapy in Parkinson's disease. Neurology, 61(3), 422-423.

Dunning, A., Ghoreyshi, A., Bertucco, M., \& Sanger, T. D. (2015). The Tuning of Human Motor Response to Risk in a Dynamic Environment Task. PLOS ONE, 10(4), e0125461. https://doi.org/10.1371/ journal.pone.0125461

Feil, J., Sheppard, D., Fitzgerald, P. B., Yücel, M., Lubman, D. I., \& Bradshaw, J. L. (2010). Addiction, compulsive drug seeking, and the role of frontostriatal mechanisms in regulating inhibitory control. Neuroscience and Biobehavioral Reviews, 35(2), 248275. https://doi.org/10.1016/j.neubiorev.2010.03.001

Ferrari, M., \& Quaresima, V. (2012). A brief review on the history of human functional near-infrared spectroscopy (fNIRS) development and fields of application. NeuroImage, 63(2), 921-935. https://doi. org/10.1016/j.neuroimage.2012.03.049

Gerlach, G., Herpertz, S., \& Loeber, S. (2015). Personality traits and obesity: A systematic review. Obesity Reviews: An Official Journal of the International Association for the Study of Obesity, 16(1), 32-63. https://doi.org/10.1111/obr.12235

Golden, C. J., \& Freshwater, S. M. (1978). Stroop color and word test. Age, 15, 90 .

Griffin, K. W., Scheier, L. M., Acevedo, B., Grenard, J. L., \& Botvin, G. J. (2012). Long-term effects of self-control on alcohol use and sexual behavior among urban minority young women. International Journal of Environmental Research and Public Health, 9(1), 1-23. https://doi.org/10.3390/ijerph9010001

Hanoch, Y., Johnson, J. G., \& Wilke, A. (2006). Domain specificity in experimental measures and participant recruitment: An application to risk-taking behavior. Psychological Science, 17(4), 300-304. https://doi. org/10.1111/j.1467-9280.2006.01702.x

Hare, T. A., Camerer, C. F., \& Rangel, A. (2009). Self-control in decision-making involves modulation of the vmPFC valuation system. Science (New York, N.Y.), 324(5927), 646-648. https://doi.org/10.1126/ science. 1168450

Harris, C. M., \& Wolpert, D. M. (1998). Signaldependent noise determines motor planning. Nature, 394(6695), 780-784. https://doi.org/10.1038/29528

Heatherton, T. F., \& Wagner, D. D. (2011). Cognitive neuroscience of self-regulation failure. Trends in
Cognitive Sciences, 15(3), 132-139. https://doi. org/10.1016/j.tics.2010.12.005

Hillman, C. H., Khan, N. A., \& Kao, S.-C. (2015). The relationship of health behaviors to childhood cognition and brain health. Annals of Nutrition \& Metabolism, 66, Suppl. 3, 1-4. https://doi.org/10.1159/000381237

Kelley, W. M., Wagner, D. D., \& Heatherton, T. F. (2015). In search of a human self-regulation system. Annual Review of Neuroscience, 38(1), 389-411. https:// doi.org/10.1146/annurev-neuro-071013-014243

Kleih, S. C., \& Kübler, A. (2013). Empathy, motivation, and P300-BCI performance. Frontiers in Human Neuroscience, 7(642), 10-3389.

Kohno, M., Morales, A. M., Ghahremani, D. G., Hellemann, G., \& London, E. D. (2014). Risky decision making, prefrontal cortex, and mesocorticolimbic functional connectivity in methamphetamine dependence. JAMA Psychiatry, 71(7), 812-820. https:// doi.org/10.1001/jamapsychiatry.2014.399

Kool, W., McGuire, J. T., Rosen, Z. B., \& Botvinick, M. M. (2010). Decision making and the avoidance of cognitive demand. Journal of Experimental Psychology. General, 139(4), 665-682. https://doi.org/10.1037/a0020198

Krain, A. L., Wilson, A. M., Arbuckle, R., Castellanos, F. X., \& Milham, M. P. (2006). Distinct neural mechanisms of risk and ambiguity: A metaanalysis of decision-making. NeuroImage, 32(1), $477-$ 484. https://doi.org/10.1016/j.neuroimage.2006.02.047

Kueider, A. M., Parisi, J. M., Gross, A. L., \& Rebok, G. W. (2012). Computerized Cognitive Training with Older Adults: A Systematic Review. PLoS ONE, 7(7), e40588. https://doi.org/10.1371/journal.pone.0040588

Lejuez, C. W., Read, J. P., Kahler, C. W., Richards, J. B., Ramsey, S. E., Stuart, G. L., ... Brown, R. A. (2002). Evaluation of a behavioral measure of risk taking: The Balloon Analogue Risk Task (BART). Journal of Experimental Psychology, 8(2), 75-84.

Lieberman, M. D. (2007). Social cognitive neuroscience: A review of core processes. Annual Review of Psychology, 58(1), 259-289. https://doi.org/10.1146/ annurev.psych.58.110405.085654

Logan, G. D., Schachar, R. J., \& Tannock, R. (1997). Impulsivity and inhibitory control. Psychological Science, 8(1), 60-64. https://doi.org/10.1111/j.1467-9280.1997. tb00545.x

Masataka, N., Perlovsky, L., \& Hiraki, K. (2015). Nearinfrared spectroscopy (NIRS) in functional research of prefrontal cortex. Frontiers in Human Neuroscience, 9. https://doi.org/10.3389/fnhum.2015.00274

Mathôt, S., Schreij, D., \& Theeuwes, J. (2012). OpenSesame: An open-source, graphical experiment builder for the social sciences. Behavior Research Methods, 44(2), 314-324. https://doi.org/10.3758/ s13428-011-0168-7

Meda, S. A., Stevens, M. C., Potenza, M. N., Pittman, B., Gueorguieva, R., Andrews, M. M., ... Pearlson, G. D. (2009). Investigating the behavioral and self-report 
constructs of impulsivity domains using principal component analysis. Behavioural Pharmacology, 20(5-6), 390-399. https://doi.org/10.1097/FBP.0b013 e32833113a3

Mickevičienė, D., Skurvydas, A., \& Karanauskienė, D. (2015). Is intraindividual variability different between unimanual and bimanual speed-accuracy movements? Perceptual and Motor Skills, 120(1), 125-138. https:// doi.org/10.2466/25.PMS.120v14x3

Miller, E. K., \& Cohen, J. D. (2001). An integrative theory of prefrontal cortex function. Annual Review of Neuroscience, 24(1), 167-202.

Moffitt, T. E., Arseneault, L., Belsky, D., Dickson, N., Hancox, R. J., Harrington, H., ... Caspi, A. (2011). A gradient of childhood self-control predicts health, wealth, and public safety. Proceedings of the National Academy of Sciences, 108(7), 2693-2698. https://doi. org/10.1073/pnas.1010076108

Monterosso, J. R., Aron, A. R., Cordova, X., Xu, J., \& London, E. D. (2005). Deficits in response inhibition associated with chronic methamphetamine abuse. Drug and Alcohol Dependence, 79(2), 273-277. https://doi. org/10.1016/j.drugalcdep.2005.02.002

Mueller, S. T., \& Piper, B. J. (2014). The Psychology of Experiment Building Language (PEBL) and PEBL Test Battery. Journal of Neuroscience Methods, 222, 250259. https://doi.org/10.1016/j.jneumeth.2013.10.024

Muraven, M., \& Baumeister, R. F. (2000). Selfregulation and depletion of limited resources: does self-control resemble a muscle? Psychological Bulletin, 126(2), 247-259.

Pascual, L., Rodrigues, P., \& Gallardo-Pujol, D. (2013). How does morality work in the brain? A functional and structural perspective of moral behavior. Frontiers in Integrative Neuroscience, 7. https://doi.org/10.3389/ fnint.2013.00065

Patton, J. H., Stanford, M. S., \& others. (1995). Factor structure of the Barratt impulsiveness scale. Journal of Clinical Psychology, 51(6), 768-774.

Pratt, J. A., Winchester, C., Egerton, A., Cochran, S. M., \& Morris, B. J. (2008). Modelling prefrontal cortex deficits in schizophrenia: implications for treatment. British Journal of Pharmacology, 153(S1), S465-S470. https://doi.org/10.1038/bjp.2008.24

Qi, X., Du, X., Yang, Y., Du, G., Gao, P., Zhang, Y., ... Zhang, Q. (2015). Decreased modulation by the risk level on the brain activation during decision making in adolescents with internet gaming disorder. Frontiers in Behavioral Neuroscience, 9. https://doi.org/10.3389/ fnbeh.2015.00296

Raine, A., \& Yang, Y. (2006). Neural foundations to moral reasoning and antisocial behavior. Social Cognitive and Affective Neuroscience, 1(3), 203-213. https://doi.org/10.1093/scan/ns1033

Reeves, D. L., Winter, K. P., Bleiberg, J., \& Kane, R. L. (2007). ANAM $®$ Genogram: Historical perspectives, description, and current endeavors. Archives of Clinical
Neuropsychology, 22, Supplement 1, 15-37. https://doi. org/10.1016/j.acn.2006.10.013

Reynolds, B., Ortengren, A., Richards, J. B., \& de Wit, H. (2006). Dimensions of impulsive behavior: Personality and behavioral measures. Personality and Individual Differences, 40(2), 305-315. https://doi.org/10.1016/j. paid.2005.03.024

Schonberg, T., Fox, C. R., Mumford, J. A., Congdon, E., Trepel, C., \& Poldrack, R. A. (2012). Decreasing Ventromedial Prefrontal Cortex Activity During Sequential Risk-Taking: An fMRI Investigation of the Balloon Analog Risk Task. Frontiers in Neuroscience, 6. https://doi.org/10.3389/fnins.2012.00080

Schultz, W., O’Neill, M., Tobler, P. N., \& Kobayashi, S. (2011). Neuronal signals for reward risk in frontal cortex. Annals of the New York Academy of Sciences, 1239(1), 109-117. https://doi.org/10.1111/j.17496632.2011.06256.x

Schutte, N. S., Malouff, J. M., Hall, L. E., Haggerty, D. J., Cooper, J. T., Golden, C. J., \& Dornheim, L. (1998). Development and validation of a measure of emotional intelligence. Personality and Individual Differences, 25(2), 167-177.

Seegelke, C., \& Schack, T. (2016). Cognitive Representation of Human Action: Theory, Applications, and Perspectives. Frontiers in Public Health, 4. https:// doi.org/10.3389/fpubh.2016.00024

Shadmehr, R., Smith, M. A., \& Krakauer, J. W. (2010). Error Correction, Sensory Prediction, and Adaptation in Motor Control. Annual Review of Neuroscience, 33(1), 89-108. https://doi.org/10.1146/annurevneuro-060909-153135

Solianik, R., Sujeta,A., Terentjevienè,A., \& Skurvydas,A. (2016). Effect of $48 \mathrm{~h}$ Fasting on Autonomic Function, Brain Activity, Cognition, and Mood in Amateur Weight Lifters. BioMed Research International, e1503956. https://doi.org/10.1155/2016/1503956

Stanford, M. S., Greve, K. W., Boudreaux, J. K., Mathias, C. W., \& L. Brumbelow, J. (1996). Impulsiveness and risk-taking behavior: Comparison of high-school and college students using the Barratt Impulsiveness Scale. Personality and Individual Differences, 21(6), 1073-1075. https://doi.org/10.1016/ S0191-8869(96)00151-1

Starcke, K., Polzer, C., Wolf, O. T., \& Brand, M. (2011). Does stress alter everyday moral decision-making? Psychoneuroendocrinology, 36(2), 210-219.

Tangney, J. P., Baumeister, R. F., \& Boone, A. L. (2004). High self-control predicts good adjustment, less pathology, better grades, and interpersonal success. Journal of Personality, 72(2), 271-324. https://doi. org/10.1111/j.0022-3506.2004.00263.x

Terry, P. C., Lane, A. M., \& Fogarty, G. J. (2003). Construct validity of the Profile of Mood States Adolescents for use with adults. Psychology of Sport and Exercise, 4(2), 125-139. https://doi.org/10.1016/ S1469-0292(01)00035-8 
Thorne, D. R. (2006). Throughput: A simple performance index with desirable characteristics. Behavior Research Methods, 38(4), 569-573. https://doi.org/10.3758/ BF03193886

Verbruggen, F., \& Logan, G. D. (2008). Response inhibition in the stop-signal paradigm. Trends in Cognitive Sciences, 12(11), 418-424. https://doi. org/10.1016/j.tics.2008.07.005

Weafer, J., Dzemidzic, M., Eiler II, W., Oberlin, B. G., Wang, Y., \& Kareken, D. A. (2015). Associations between regional brain physiology and trait impulsivity, motor inhibition, and impaired control over drinking. Psychiatry Research: Neuroimaging, 233(2), 81-87. https://doi.org/10.1016/j.pscychresns.2015.04.010

Wolpert, D. M., \& Landy, M. S. (2012). Motor control is decision-making. Current Opinion in Neurobiology, 22(6), 996-1003. https://doi.org/10.1016/j. conb.2012.05.003
Woodhouse, J., Heyanka, D. J., Scott, J., Vincent, A., Roebuck-Spencer, T., Domboski-Davidson, K., ... Adams, R. (2013). Efficacy of the ANAM General Neuropsychological Screening battery (ANAM GNS) for Detecting Neurocognitive Impairment in a Mixed Clinical Sample. The Clinical Neuropsychologist, 27(3), 376-385. https://doi.org/10.1080/13854046.2012.762427

Zald, D. H., Cowan, R. L., Riccardi, P., Baldwin, R. M., Ansari, M. S., Li, R., ... Kessler, R. M. (2008). Midbrain Dopamine Receptor Availability Is Inversely Associated with Novelty-Seeking Traits in Humans. Journal of Neuroscience, 28(53), 14372-14378. https://doi. org/10.1523/JNEUROSCI.2423-08.2008

Zuoza, A., Skurvydas, A., Mickeviciene, D., Gutnik, B., Zouzene, D., Penchev, B., \& Pencheva, S. (2009). Behavior of dominant and non dominant arms during ballistic protractive target-directed movements. Human Physiology, 35(5), 576-584. https://doi.org/10.1134/ S0362119709050090
Corresponding author Dalia Mickevičienè Institute of Sports Science and Innovations Lithuanian Sports University Sporto str. 6, Kaunas LT-44221

Lithuania

Tel. +37060073021

Fax +37037204515

Email dalia.mickeviciene@1su.lt 